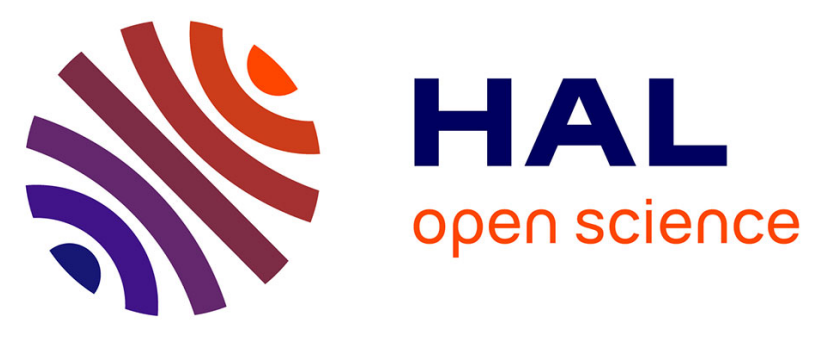

\title{
Identification of a Novel Secretogranin II-Derived Peptide (SgII 187-252 ) in Adult and Fetal Human Adrenal Glands Using Antibodies Raised against the Human Recombinant Peptide*
}

Youssef Anouar, Christine Desmoucelles, Laurent Yon, Jérôme Leprince, Lyne Breault, Nicole Gallo-Payet, Hubert Vaudry

\section{To cite this version:}

Youssef Anouar, Christine Desmoucelles, Laurent Yon, Jérôme Leprince, Lyne Breault, et al.. Identification of a Novel Secretogranin II-Derived Peptide (SgII 187-252) in Adult and Fetal Human Adrenal Glands Using Antibodies Raised against the Human Recombinant Peptide*. Journal of Clinical Endocrinology and Metabolism, 1998, 83, pp.2944 - 2951. hal-01706428

\section{HAL Id: hal-01706428}

https://hal-normandie-univ.archives-ouvertes.fr/hal-01706428

Submitted on 20 Jul 2018

HAL is a multi-disciplinary open access archive for the deposit and dissemination of scientific research documents, whether they are published or not. The documents may come from teaching and research institutions in France or abroad, or from public or private research centers.
L'archive ouverte pluridisciplinaire HAL, est destinée au dépôt et à la diffusion de documents scientifiques de niveau recherche, publiés ou non, émanant des établissements d'enseignement et de recherche français ou étrangers, des laboratoires publics ou privés. 


\title{
Identification of a Novel Secretogranin II-Derived Peptide (SgII 187-252 ) in Adult and Fetal Human Adrenal Glands Using Antibodies Raised against the Human Recombinant Peptide*
}

\author{
YOUSSEF ANOUAR, CHRISTINE DESMOUCELLES $\dagger$, LAURENT YON, \\ JEROME LEPRINCE $\ddagger$ LYNE BREAULT§, NICOLE GALLO-PAYET, AND \\ HUBERT VAUDRY
}

European Institute for Peptide Research (IFRMP 23), Laboratory of Cellular and Molecular Neuroendocrinology, INSERM U-413, UA Centre National de la Recherche Scientifique, University of Rouen (Y.A., C.D., L.Y., J.L., H.V.), 76821 Mont-Saint-Aignan, France; and the Service of Endocrinology, Department of Medicine, Faculty of Medicine, University of Sherbrooke (L.B., N.G.-P.), Sherbrooke, Quebec, Canada J1H 5N4

\begin{abstract}
Molecular cloning of secretogranin II (SgII) in phylogenetically distant species has recently revealed the existence of a highly conserved 66-amino acid peptide flanked by preserved pairs of basic residues. This observation suggested that this peptide, named EM66, which had not been described to date, could be an important processing product of SgII. The aim of the present study was to investigate the possible occurrence of EM66 in the human adrenal gland. The EM66 peptide was generated in Escherichia coli, which was programmed to make a fusion protein containing the human EM66 sequence. The affinity-purified fusion protein was used to raise polyclonal antibodies in rabbits. The free EM66 peptide was obtained by cleavage of the fusion protein followed by high performance liquid chromatography purification. Immunohistochemical analysis using
\end{abstract}

$\mathrm{T}$ HE TERM granins (chromogranins/secretogranins) designates a family of secretory polypeptides stored in large dense-core vesicles of neurons and endocrine cells (13). Almost all these cells contain at least one member of the granin family, making these proteins useful markers for the identification of neuroendocrine cells and neoplasms $(4,5)$. The function of granins has long remained elusive until the cloning of their respective complementary DNA (cDNA) the EM66 antibodies revealed intense labeling of adrenochromaffin cells in the adult adrenal medulla and the fetal adrenal gland. A sensitive and specific RIA was developed and applied to the detection of EM66-like immunoreactivity in extracts of adult adrenal medulla and whole fetal adrenal gland after high performance liquid chromatographic analysis. A major immunoreactive species exhibiting the same retention time as recombinant EM66 was detected in both adult and fetal adrenal extracts. Taken together, these data demonstrate that posttranslational processing of SgII actually generates EM66 in the adrenal gland. The strong conservation of the amino acid sequence of EM66 in the vertebrate phylum and the occurrence of the mature peptide in both fetal and adult chromaffin cells suggest that EM66 could play an important physiological role in the human adrenal gland.

revealed that these proteins contain several pairs of basic amino acids that represent potential cleavage sites for prohormone convertases (PCs). In particular, secretogranin II (SgII) possesses nine pairs of basic residues in mammals, suggesting that the protein may serve as a precursor to novel neuropeptides (6-9).

The cDNA encoding SgII has been recently characterized in two amphibian species, the frog Rana ridibunda (10) and the toad Xenopus laevis (11). Comparison of the amino acid sequences of human and amphibian SgII revealed that evolutionary pressure has acted to conserve particularly the structures of two putative peptides bounded by dibasic residues, whereas other domains of SgII have been poorly preserved across vertebrate species $(10,11)$. One of the conserved peptides, dubbed secretoneurin $\left(\mathrm{SN}\right.$; $\mathrm{SgII}_{152-184}$ in the human sequence), has received much attention. The peptide has been isolated and characterized in the frog brain and thus identified as an authentic processing product of SgII (12).

Subsequently, the occurrence of SN has been demonstrated in a wide range of tissues $(13,14)$, and the peptide has been shown to exert various biological activities (15-19). In contrast, the second conserved region corresponding to a 66-amino acid peptide flanking SN at its C-terminal extrem- 
ity (Fig. 1) has not yet been investigated. This peptide, called EM66, is delimited by conserved dibasic cleavage sites, and the structures of human and amphibian EM66 exhibit 68$70 \%$ sequence identity $(10,11)$.

As SgII is expressed in adrenochromaffin cells $(3,20)$, and high amounts of SgII are found in specific adrenal disorders such as ganglioneuromas (21), we sought in this study to characterize EM66 in the human adrenal gland. A fusion protein containing the human EM66 peptide was produced in Escherichia coli and used to raise polyclonal antibodies directed against EM66. These antibodies were employed to localize EM66-producing cells and to characterize the native peptide in adult and fetal human adrenal glands.

\section{Materials and Methods}

\section{Production of recombinant EM66 and the cognate antibody}

The cDNA sequence encoding the EM66 region in human SgII was amplified by PCR using $75 \mathrm{ng}$ of the plasmid human SgII-Bluescript (22) and 50 pmol of the sense primer EM11 (5'-GAGAGGATGGATGAGGAGCAAAAAC- $3^{\prime}$ ) and the antisense primer EM3 (5'-CTAGAAGCTTACATCTCATCGTTGATTTGTTCAT-3'). A stop codon and a HindIII restriction site necessary for the production of the peptide and for subcloning, respectively (see below), were introduced at the $5^{\prime}$-end of the antisense primer. DNA amplification was carried out in a reaction mixture containing $67 \mathrm{mmol} / \mathrm{L}$ Tris- $\mathrm{HCl}\left(\mathrm{pH} \mathrm{8.8)}, 16 \mathrm{mmol} / \mathrm{L}\left(\mathrm{NH}_{4}\right)_{2} \mathrm{SO}_{4}\right.$, $1.5 \mathrm{mmol} / \mathrm{L} \mathrm{MgCl}_{2}, 0.01 \%$ Tween-20, $200 \mu \mathrm{mol} / \mathrm{L}$ deoxy-NTP, and 2.5 U Taq DNA polymerase (Eurobio, Les Ulis, France) in the following conditions: denaturation at $94 \mathrm{C}$ for $4 \mathrm{~min}$ followed by 30 cycles of 94 $\mathrm{C}$ for $1 \mathrm{~min}, 60 \mathrm{C}$ for $1 \mathrm{~min}$, and $72 \mathrm{C}$ for $1 \mathrm{~min}$ before a final extension step at $72 \mathrm{C}$ for $7 \mathrm{~min}$. The PCR product was purified, its ends were blunted with Pfu DNA polymerase (Stratagene, La Jolla, CA), and it was digested with HindIII before ligation into the expression plasmid pMAL-c2 (New England Biolabs, Beverly, MA) previously cut with $\mathrm{X} m n \mathrm{I}$ and HindIII. The construction was verified by DNA sequencing through the EM66 region. This strategy allows for the subcloning of EM66-encoding DNA in the sense orientation, in frame with and downstream of the plasmid region encoding the bacterial maltose-binding protein (MBP). The MBP-EM66 fusion protein was expressed in isopropyl D-thiogalactopyranoside (IPTG)-induced E. coli and affinity purified from bacterial soluble extracts applied to amylose resin essentially as described by the manufacturer of the Protein Fusion and Purification System (New England Biolabs).

The purified fusion protein was cleaved by factor Xa $(1 \mu \mathrm{g} / 100 \mu \mathrm{g}$ fusion protein) to release EM66. The recombinant peptide was submitted to partial purification on Sep-Pak $C_{18}$ cartridges (Waters, St-Quentin en Yvelines, France). Bound peptide was eluted from the cartridges with acetonitrile/water/trifluoroacetic acid (TFA; 30:69.9:0.1, vol/vol/vol) and lyophilized. The Sep-Pak-prepurified recombinant peptide was re- dissolved in $1 \mathrm{~mL} \mathrm{10 \%} \mathrm{acetonitrile} \mathrm{in} \mathrm{water} \mathrm{(vol/vol)} \mathrm{and} \mathrm{injected} \mathrm{onto}$ a $1 \times 25-\mathrm{cm}$ reverse phase $\mathrm{Vydac} \mathrm{C}_{18}$ high performance liquid chromatography (HPLC) column (Bio-Rad, Ivry-sur-Seine, France) equilibrated with acetonitrile-water-TFA (20:79.9:0.1, vol/vol/vol) at a flow rate of $5 \mathrm{~mL} / \mathrm{min}$. The concentration of acetonitrile in the eluting solvent was held at $20 \%$ for $5 \mathrm{~min}$ and raised to $40 \%$ over $65 \mathrm{~min}$. The purified recombinant peptide was characterized by analytical reverse phase HPLC $(1 \mathrm{~mL} / \mathrm{min})$ onto a $0.45 \times 25-\mathrm{cm}$ Vydac $\mathrm{C}_{18}$ column (Bio-Rad) using a linear acetonitrile gradient (10-60\% over $25 \mathrm{~min}$ ) and by mass spectrometry using a Nermag R10-10U equipped with an API-ESI from Analytica-Branford (Quad Service, Poissy, France).

Antibodies against EM66 were raised by injecting New Zealand rabbits with the fusion protein MBP-EM66 emulsified with Freund's adjuvant.

\section{SDS-PAGE and Western blot analysis}

Proteins were analyzed by PAGE under denaturing conditions (23) and either stained with Coomassie blue (Bio-Rad) or electroblotted onto a nitrocellulose sheet (Amersham, Courtaboeuf, France) and revealed with antibodies, as described previously (24), using a chemiluminescence detection kit (Amersham).

\section{Tissue preparation}

Adult human adrenal glands were obtained from patients undergoing nephrectomy for kidney cancer. For biochemical studies, the adrenal medulla was dissected from the adrenal cortex. Fetal adrenal glands were obtained from fetuses, aged 17-20 weeks (postconception), at the time of therapeutic abortion. Fetal age was estimated by foot length and time after the last menstruation, according to the method of Streeter et al. (25). After collection, glands were frozen at $-80 \mathrm{C}$. The protocols of collection of the tissues were approved by the human subject review committee at our Institutions.

\section{Immunohistochemical procedure}

Frozen adrenal glands were sliced into $10-\mu \mathrm{m}$ sections with a cryomicrotome (Frigocut, Reicher-Jung, Germany). Sections were thaw mounted on gelatin-coated slides, dried in a desiccator overnight at $4 \mathrm{C}$, and dipped for $3 \mathrm{~h}$ in McLean's fixative [ $4 \%$ paraformaldehyde, 20 $\mathrm{mmol} / \mathrm{L}$ lysine, and $2.5 \mathrm{mmol} / \mathrm{L}$ sodium metaperiodate in $0.1 \mathrm{~mol} / \mathrm{L}$ phosphate buffer (PB), $\mathrm{pH} 7.4]$. After several rinses in $\mathrm{PB}$, slices were processed for indirect immunofluorescence microscopy, as previously described (26). Briefly, tissue sections were incubated overnight at $4 \mathrm{C}$ with the EM66 antiserum (code no. 736-1806) diluted 1:500 or with antibodies against human chromogranin A (CgA; Dako, Glostrup, Denmark) diluted 1:500 in PB containing 0.3\% Triton X-100 and 1\% BSA. The tissues were rinsed in PB buffer for $30 \mathrm{~min}$ and incubated for $1 \mathrm{~h}$ at room temperature with fluorescein isothiocyanate-conjugated goat antirabbit $\gamma$-globulins (Caltag Laboratories, San Francisco, CA) diluted 1:100. Finally, adrenal slices were rinsed in PB, mounted with buffer/glycerol

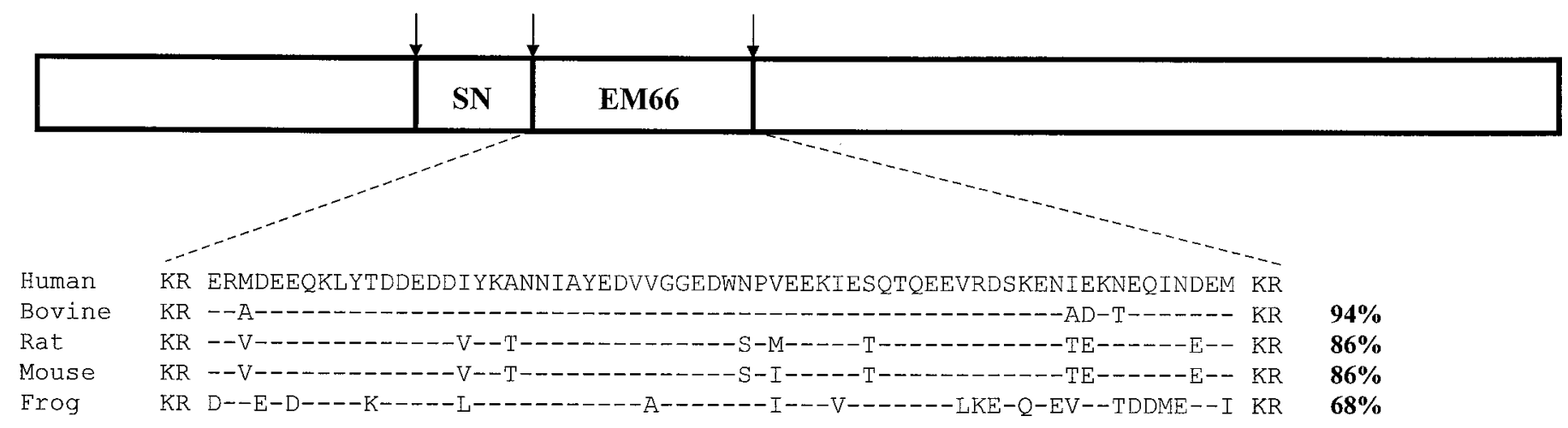

FIG. 1. Schematic representation of the structure of human SgII showing the location of SN and EM66 and the alignment of the sequence of the latter peptide in representative vertebrate species. The arrows indicate the Lys-Arg pairs at positions 150-151, 185-186, and 253-254 of human SgII (6). Dashes denote residue identity. The percentages of amino acid identity are indicated on the right. 
(1:1), coverslipped, and observed on a Leitz Orthoplan microscope (Leitz, Heidelberg, Germany) equipped with a Vario-Orthomat photographic system. To verify the specificity of the immunoreaction, the following controls were performed: 1 ) substitution of the primary antisera with $\mathrm{PB}, 2$ ) incubation with nonimmune rabbit serum instead of the EM66 or CgA antisera, and 3) preincubation of the EM66 antiserum (diluted 1:500) with purified recombinant EM66 $\left(10^{-6} \mathrm{~mol} / \mathrm{L}\right)$

\section{Tissue extraction}

For Western blot analysis, adult adrenomedullary tissue or whole fetal adrenal glands were homogenized in $10 \mathrm{mmol} / \mathrm{L}$ Tris- $\mathrm{HCl}, \mathrm{pH} 7.4$, containing $0.05 \%$ Triton $\mathrm{X}-100$ and $1 \mathrm{mmol} / \mathrm{L}$ phenylmethylsulfonylfluoride. The extracts were centrifuged at $12,000 \times g$ for $15 \mathrm{~min}$ at 4 $\mathrm{C}$, and the proteins were contained in the supernatants were analyzed.

For HPLC analysis, frozen fetal adrenal or adult adrenal medulla were immersed for $10 \mathrm{~min}$ in a cooled solution of $75 \%$ ethanol- $18 \%$ hydrochloric acid. The tissue samples were homogenized, sonicated, and centrifuged $(13,000 \times g, 4 \mathrm{C})$ for $30 \mathrm{~min}$. The supernatant was collected, dried by vacuum centrifugation (Speed-Vac Concentrator, Savant AES 2000, Hicksville, NY), and kept dry until chromatographic analysis.

\section{HPLC analysis}

Dried samples were reconstituted in $2 \mathrm{~mL} 0.1 \%$ TFA in water (solution A) and loaded onto three Sep-Pak $C_{18}$ cartridges. The cartridges were rinsed with $20 \mathrm{~mL}$ solution $\mathrm{A}$, and the bound material was eluted with $5 \mathrm{~mL}$ of a solution of acetonitrile-water-TFA (49.9:50:0.1, vol/vol/vol). The solvent was evaporated in a Speed-Vac Concentrator. The samples were reconstituted in $500 \mu \mathrm{L}$ solution $\mathrm{A}$ and centrifuged $(14,000 \times g)$, and the supernatant was injected onto a $0.45 \times 25$ - $\mathrm{cm}$ Vydac $\mathrm{C}_{18}$ column equilibrated with a solution of acetonitrile-water-TFA (9.9:90:0.1, vol/ $\mathrm{vol} / \mathrm{vol}$ ) at a flow rate of $1 \mathrm{~mL} / \mathrm{min}$. The concentration of acetonitrile in the eluting solvent was raised to $60 \%$ over 25 min using a linear gradient. HPLC standard consisted of $1 \mu \mathrm{g}$ purified recombinant EM66. Fractions of $0.5 \mathrm{~mL}$ were collected, evaporated, and kept dry until RIA.

\section{RIA}

EM66 RIA was performed with the antiserum EM66-736-1806. Purified recombinant EM66 was iodinated by the chloramine-T method and separated from free iodine on Sep-Pak $\mathrm{C}_{18}$ cartridges using a gradient of acetonitrile $(0-100 \%)$ in $0.1 \%$ TFA. The radioiodinated peptide eluted at $32 \%$ acetonitrile.

The assay was performed in standard diluent consisting of 60 $\mathrm{mmol} / \mathrm{L} \mathrm{Na} \mathrm{HPO}_{4}, 10 \mathrm{mmol} / \mathrm{L}$ ethylenediamine tetraacetate, $0.5 \%$ $\mathrm{NaN}_{3}$, and $0.1 \%$ Triton X-100 (pH 7.4). The antiserum, used at a final dilution of 1:60,000, was incubated with 6,000 cpm of tracer/tube for $48 \mathrm{~h}$ at $4 \mathrm{C}$ in the absence or presence of standard (purified EM66) or tissue extracts. Separation of antibody-bound from free peptide was achieved by adding $100 \mu \mathrm{L} \gamma$-globulins $(10 \mathrm{mg} / \mathrm{mL})$ and $2 \mathrm{~mL}$ of a $20 \%$ polyethylene glycol 6000 solution in standard diluent without Triton X-100. After a 20 -min incubation at room temperature, the samples were centrifuged $(5,000 \times g, 20 \mathrm{~min}, 4 \mathrm{C})$, and the precipitates were counted in an LKB scintillation spectrometer (LKB, Rockville, MD).

\section{Results}

Production and purification of the recombinant peptide EM66

The EM66 peptide was produced in E. coli as a fusion protein downstream of the bacterial MBP. The sequence encoding EM66 in the human SgII cDNA was amplified by PCR with specific primers (data not shown) and inserted immediately downstream of the MBP sequences so that the cleavage of the fusion protein with factor Xa would release EM66 with the native amino acid sequence. The different steps of fusion protein production and purification were monitored by SDS-PAGE (Fig. 2). The IPTG-induced fusion protein (Fig.
2, lanes 1 and 2) appeared at a relative mass of approximately $60 \mathrm{~K}$. This soluble protein was enriched by centrifugation (Fig. 2, lanes 3 and 4) and purified by affinity chromatography (Fig. 2, lane 5). The apparent mass of the recombinant protein was higher than would be expected for a fusion protein comprising the bacterial $\operatorname{MBP}(43 \mathrm{~K}$; Fig. 2, lane 6) and the 66 -amino acid peptide $(\sim 8 \mathrm{~K})$. However, it is well known that the SgII molecule has an anomalous migration in SDSPAGE due to its high content in acidic amino acids (3). It can thus be assumed that the high proportion of acidic residues in the EM66 peptide also influenced the fusion protein behavior in SDS-PAGE. Cleavage of this fusion protein by factor Xa yielded the 43K-MBP and a major peptide with an apparent molecular mass of about 13K (Fig. 3, lanes 1 and 2).

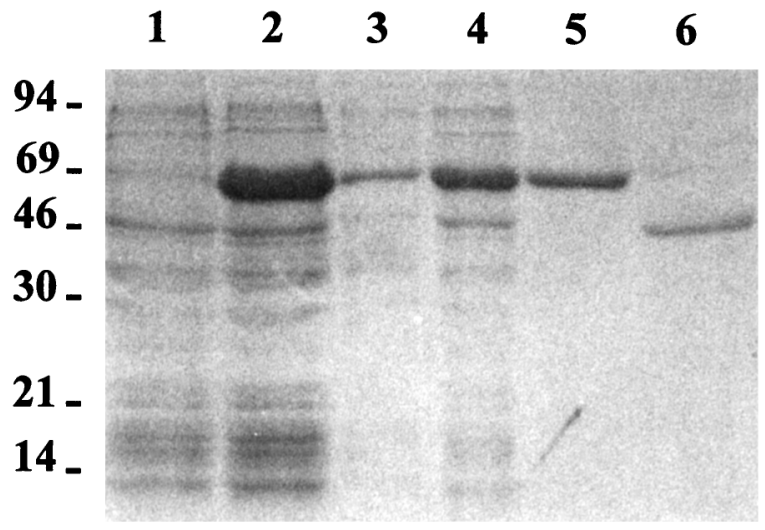

FIG. 2. SDS-PAGE analysis of the MBP-EM66 fusion protein during the purification steps. $E$. coli transformed with pMAL-c2 containing the EM66-encoding sequence (see Materials and Methods) was grown in the absence (lane 1) or presence of IPTG (lane 2), and total proteins were analyzed. The IPTG-treated bacteria were harvested and centrifuged, and the insoluble (lane 3) or soluble (lane 4) fractions were analyzed. MBP-EM66 was purified from soluble bacterial extracts by affinity chromatography on an amylose resin column (lane 5) and compared to free MBP (lane 6). Proteins were stained with Coomassie blue. Molecular mass markers in kilodaltons are indicated on the left.

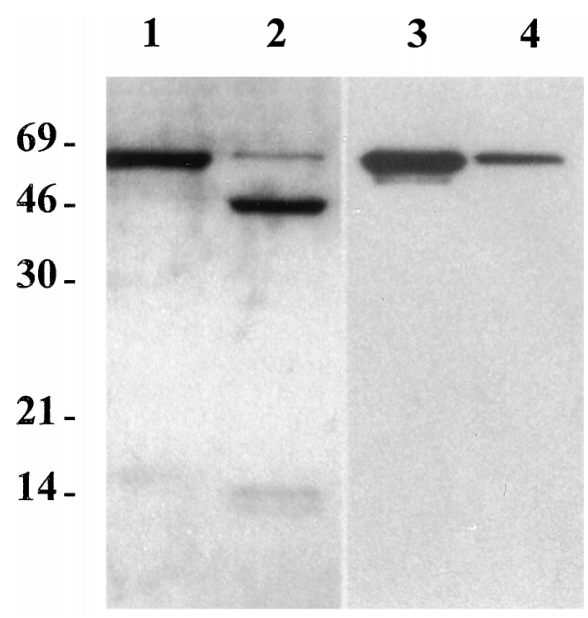

FIG. 3. The fusion protein was analyzed by Coomassie blue staining (lanes 1 and 2) or Western blot (lanes 3 and 4) after SDS-PAGE. Affinity-purified MBP-EM66 $(\sim 1.5 \mu \mathrm{g})$ was either untreated (lanes 1 and 3 ) or treated with factor Xa (lanes 2 and 4). In the Western blot analysis, the antiserum VV493-P was used at a 1:800 dilution. Molecular mass markers in kilodaltons are indicated on the left. 
Unexpectedly, a second minor peptide with a slightly lower apparent mass was also observed (Fig. 3, lane 2). To ascertain that the fusion protein actually contained the EM66 peptide, Western blot analysis was performed using a polyclonal antibody raised against a large portion of human SgII (22), including the EM66 region. This antibody recognized the $60 \mathrm{~K}$ fusion protein (Fig. 3, lane 3). As the antibody did not show any nonspecific staining of the MBP after factor Xa cleavage of the fusion protein (Fig. 3, lane 4), it was concluded that EM66 was included within the fusion protein. It was not possible to detect the free EM66 peptide itself with the human SgII antibody in this analysis, probably because it was not retained during the electrotransfer. The occurrence of a shorter peptide, in addition to EM66 after factor Xa cleavage, as observed on SDS-PAGE, could thus be ascribed to a secondary cleavage site within EM66 in addition to the site present at the boundary of MBP and EM66 in the fusion protein.

To purify the recombinant peptide from MBP, we first analyzed the factor Xa-digested fusion protein on an analytical Vydac $\mathrm{C}_{18}$ HPLC column. This chromatography confirmed the presence of an EM66 doublet (Fig. 4A). The major recombinant peptide was then chromatographed to apparent homogeneity onto a semipreparative Vydac $\mathrm{C}_{18}$ column (data not shown). The purified peptide eluted as a sharp peak on an analytical Vydac $\mathrm{C}_{18}$ HPLC column (Fig. 4B). Mass spectrometric analysis assigned a molecular mass of 7884.08 to this purified peptide (data not shown) compared to a calculated mass of 7884 for the full-length EM66. The discrepancy between this value and the relative mass observed by SDS-PAGE analysis $(\sim 13 \mathrm{~K})$ confirmed the anomalous migration of EM66 on SDS-PAGE.

\section{Characterization of the EM66 antiserum}

Polyclonal antibodies were raised in rabbits against the fusion protein MBP-EM66. The sensitivity and specificity of the EM66 antibodies generated were determined by RIA (Fig. 5). The sensitivity threshold of the assay was between $25-100$ pg (3.2-12.8 fmol)/tube. The antiserum did not exhibit any significant cross-reactivity with pituitary adenylate cyclaseactivating polypeptide (PACAP), calcitonin gene-related peptide (CGRP), galanin, or the other human SgII-derived peptide, SN.

A Western blot analysis of adult and fetal human adrenal extracts was performed to determine the cross-reactivity of the EM66 antibodies with SgII and its intermediate processing products. The antiserum revealed, in addition to human SgII, which migrates at an apparent molecular mass of $97 \mathrm{~K}$ (22), several bands of lower molecular mass ranging from about $80-13 \mathrm{~K}$ in both adult and fetal human adrenal extracts (Fig. 6). The band at 13K may correspond to the EM66 peptide.

\section{Immunohistochemical detection of EM66 in the human adrenal gland}

Immunofluorescence labeling of adult human adrenal slices with the antiserum against EM66 produced intense staining of medullary cells, whereas adrenocortical cells were totally devoid of immunoreactivity (Fig. 7A). Labeling
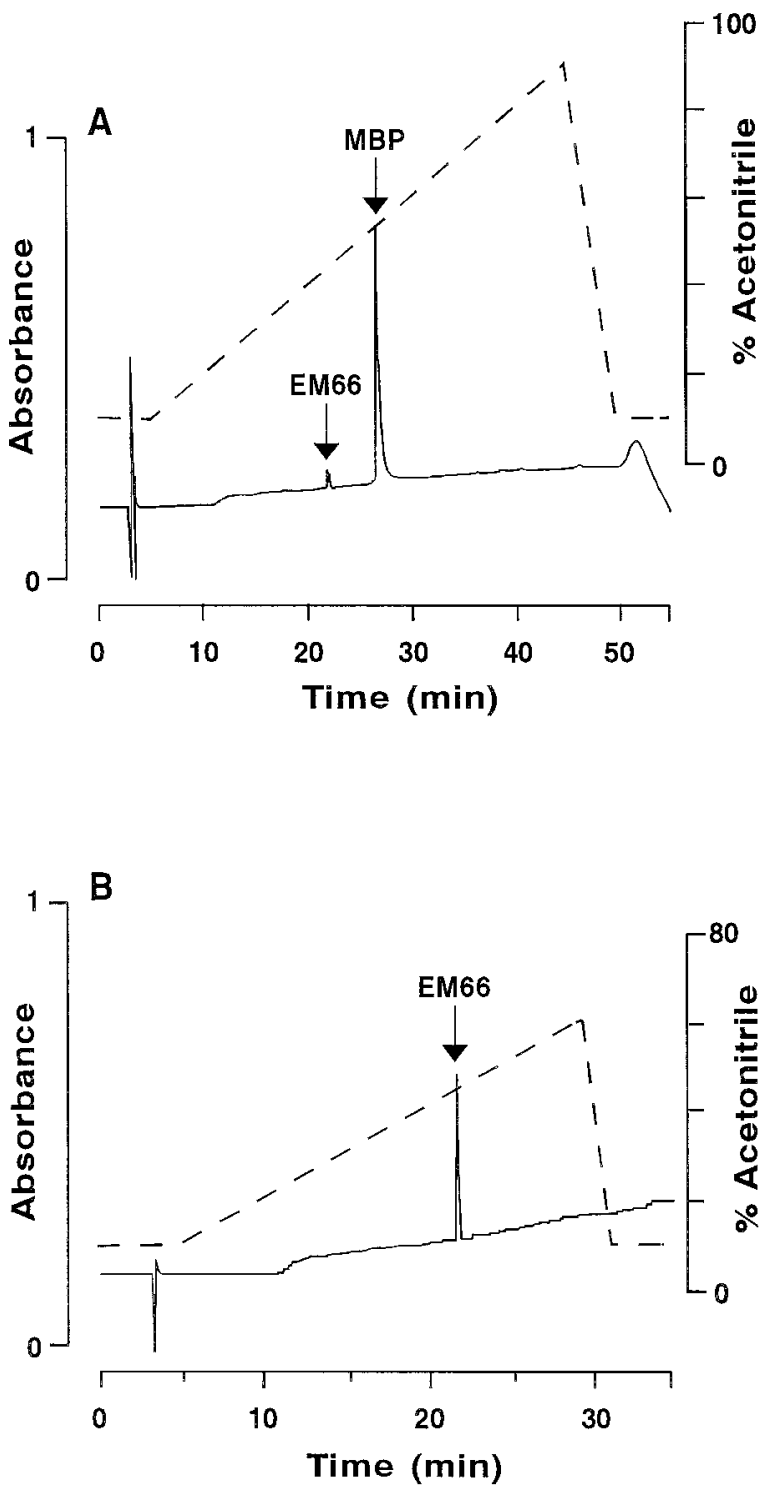

Fig. 4. A, Analytical reverse phase HPLC analysis of MBP-EM66 after cleavage by factor Xa showing the MBP protein and the EM66 peptide doublet indicated by arrows. B, Analytical reverse phase HPLC analysis of the major recombinant EM66 peptide after purification on a semipreparative Vydac $\mathrm{C}_{18}$ column as described in $M a$ terials and Methods. The dashed lines show the concentration of acetonitrile in the eluting solvents.

of consecutive sections with an antiserum against $\mathrm{CgA}$ (a selective marker of chromaffin cells) confirmed that the EM66-like immunoreactivity was restricted to the medulla (Fig. 7B).

In the fetal adrenal gland, the EM66 antiserum revealed the presence of clusters of positive cells (Fig. 7C). Incubation of consecutive sections with antibodies against human $\mathrm{CgA}$ labeled the same nests of cells (data not shown), indicating that the EM66-immunopositive cells actually correspond to chromaffin progenitor cells. Steroid-producing cells of the outer neocortex and the large fetal zone were not immunolabeled (Fig. 7C). Preabsorption of the EM66 antiserum with $10^{-6} \mathrm{~mol} / \mathrm{L}$ EM66 totally abolished the immunoreaction (Fig. 7D). When the antiserum was substituted with either 


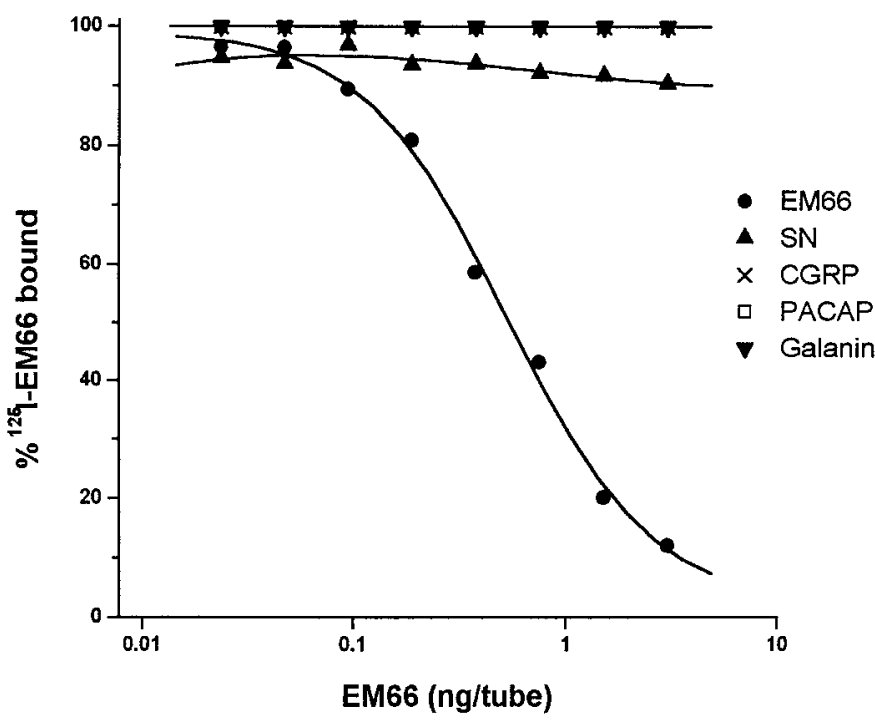

FIG. 5. Characterization of the antibodies directed against MBPEM66 by RIA. Antibody-bound ${ }^{125}$ I-labeled EM 66 was displaced by increasing amounts of purified recombinant EM66. SN, CGRP, PACAP, and galanin were tested for cross-reactivity.

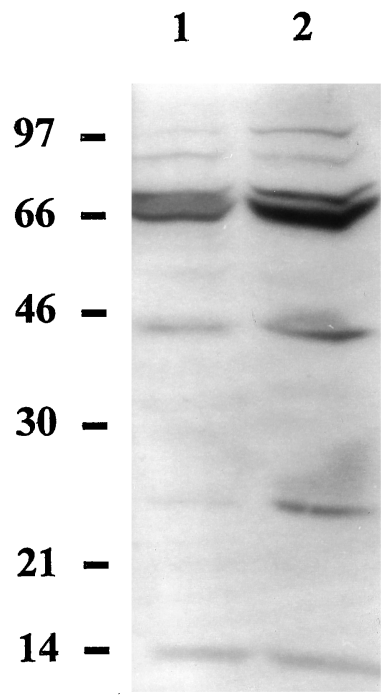

FIG. 6. Western blot analysis of adult (1) and fetal (2) human adrenal gland extracts. Tissue samples were homogenized, and proteins $(30-50 \mu \mathrm{g})$ from $12,000 \times g$ supernatants were analyzed by SDSPAGE followed by immunoblotting using EM66 antibodies at a 1:2000 dilution. Molecular mass markers in kilodaltons are indicated on the left.

nonimmune rabbit serum or $\mathrm{PB}$, no immunofluorescence was observed.

\section{Characterization of EM66-like material in human adrenal extracts}

Adult and fetal human adrenal gland extracts were analyzed by HPLC, and the EM66-like immunoreactivity contained in the eluted fractions was quantified by RIA (Fig. 8). The chromatograms revealed the existence of a major peak of EM66-immunoreactive material exhibiting the same retention time as recombinant EM66 in both adult (Fig. 8A) and fetal (Fig. 8B) adrenal gland extracts. However, although the adult adrenal gland extract contained a single immunoreactive peak, several minor components exhibiting EM66-like immunoreactivity were resolved in the fetal adrenal gland extract.

\section{Discussion}

The present study demonstrates that a peptide of 66 amino acids contained within the human SgII protein sequence is actually produced in the human adrenal gland.

The recent characterization of the cDNA encoding SgII in the frog Rana ridibunda has revealed that the sequence of four peptides, delimited by pairs of basic amino acids, has been remarkably preserved across vertebrates (10). Selective regional conservation of the sequence of SgII has also been reported in the toad Xenopus laevis, particularly for two regions that are also highly preserved in frog, i.e. the neuropeptide SN and the peptide EM66, which has not been investigated previously (11).

As the large size of EM66 precluded its chemical synthesis, the peptide was produced in E. coli. The identity of the recombinant peptide was verified by Western blot and mass spectrometric analysis, thus validating the molecular strategy employed. Recombinant EM66 exhibited abnormal migration on SDS-PAGE with an apparent mass of approximately 13K compared to a molecular mass of 7884.08 as determined by mass spectrometry. This anomalous behavior on SDS-PAGE, which has been described for the whole SgII protein as well as for other members of the granin family, can be ascribed to the acidic nature of these proteins (1-3).

A sensitive and specific RIA has been developed using antibodies raised against a fusion protein comprising EM66 and a bacterial protein. These antibodies did not show any cross-reactivity with various peptides present in the adrenal medulla such as galanin, PACAP, CGRP, or SN (27-29). Analysis of human adrenal extracts by Western blotting revealed that the EM66 antibodies recognize to some extent human $\mathrm{SgII}$ and intermediate processing products. Combination of HPLC analysis and RIA detection was used to characterize EM66 in adult and fetal human adrenal extracts. An immunoreactive peak exhibiting the same retention time as recombinant EM66 was found in both adult and fetal gland extracts. These data indicate that in the human adrenal gland, SgII serves as a precursor to generate the peptide EM66. Within SgII, the sequence of EM66 is flanked by Lys-Arg dibasic sites, which are efficient cleavage sites for PCs in other hormone and neuropeptide precursors (30). The processing of EM66 at the N-terminal Lys-Arg was predictable because the latter is shared with $\mathrm{SN}$, which has been shown to occur in the human adrenal (29). The fact that EM66 is formed in the human adrenal shows that the C-terminal Lys-Arg site of this peptide is also processed. This finding contributes to the identification of the pairs of basic amino acids of SgII that are actually cleaved, as it has been shown that not all of these sites are processed $(13,31)$. Complete characterization of the sites of SgII that are cleaved in vivo will undoubtedly facilitate the study of the function of SgII and its derived peptides.

Although a single immunoreactive form coeluting with EM66 was found in the adult adrenal medulla extract, several 

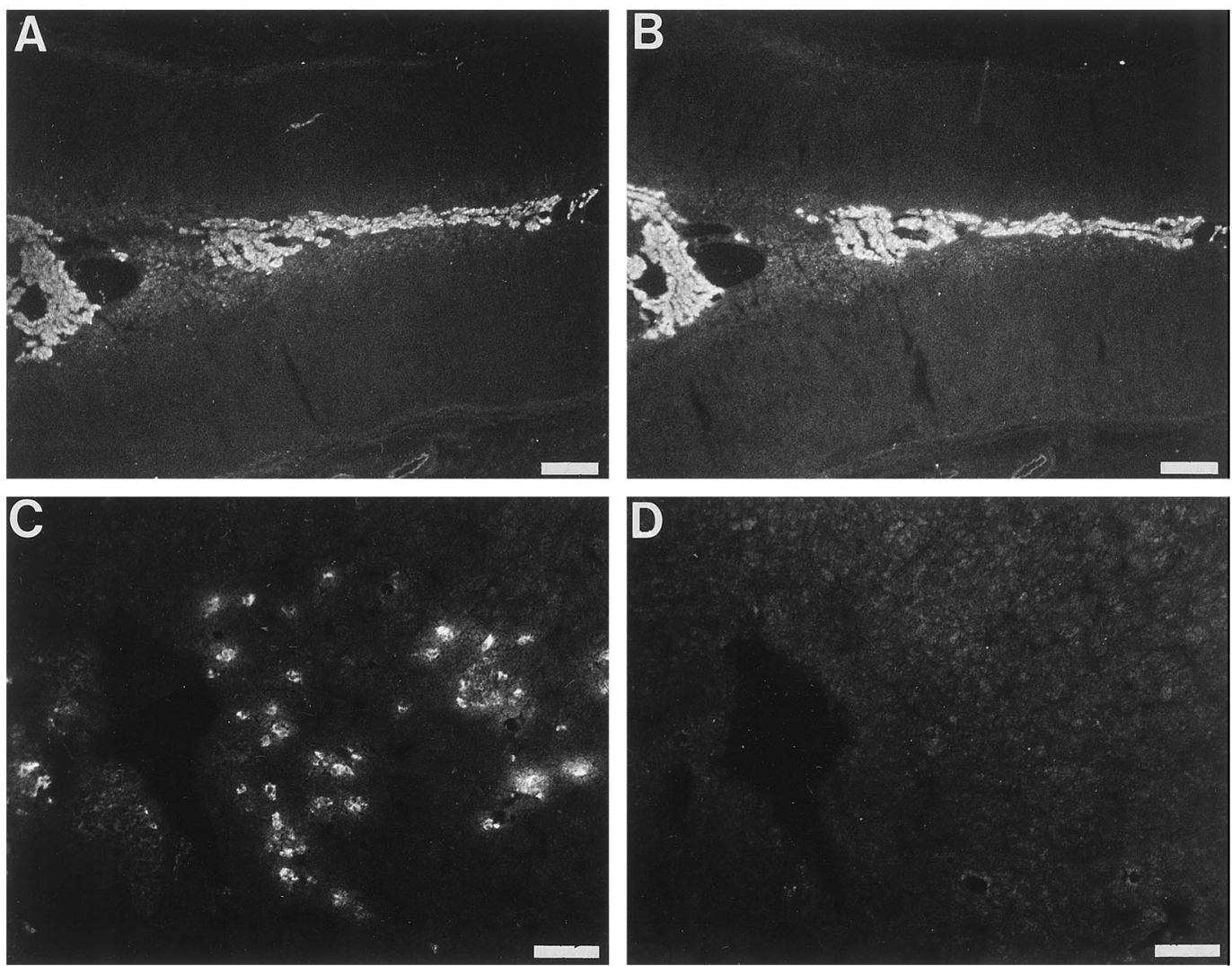

FIG. 7. Immunofluorescence labeling of EM66 in adult and fetal human adrenal glands. A and B, Consecutive sections of an adult adrenal gland incubated with the antiserum against EM66 (A) or an antiserum against CgA (B). Both antisera produced intense labeling of the medullary zone. $\mathrm{C}$ and D, Consecutive sections of a fetal adrenal gland incubated with the EM66 antiserum (C) or with the same antiserum preabsorbed overnight with $10^{-6} \mathrm{~mol} / \mathrm{L}$ purified EM66 (D). Bars $=100 \mu \mathrm{m}(\mathrm{A}$ and B) and $500 \mu \mathrm{m}(\mathrm{C}$ and D).

minor peaks exhibiting shorter retention times than EM66 were also detected in the fetal adrenal extract. The early elution position of these immunoreactive peptides suggests that they may correspond to truncated forms of EM66.

Immunohistochemical staining of human adrenal slices with the EM66 antiserum revealed intense labeling of the adrenomedullary cells in the adult gland and nests of cells in the fetal zone of the developing adrenal. Labeling of consecutive sections with an antibody against $\mathrm{CgA}$ confirmed that in both the adult and fetal adrenal glands, the EM66immunoreactive material was contained in adrenochromaffin cells. These observations along with the HPLC data indicate that EM66 can be generated early during development of the human adrenal gland. Consistent with this finding, it has been recently reported that $\mathrm{SgII}$ is processed to the free peptide $\mathrm{SN}$ at all developmental stages of the rat brain (32).

The existence of EM66 strengthens the concept that SgII is processed in vivo to give rise to several peptides that might play a role in the nervous, neuroendocrine, and endocrine systems. In fact, SgII exhibits most of the characteristics of neuropeptide precursors. First, SgII is exclusively expressed in endocrine and neuronal cells and is stored in secretory vesicles from which it is released upon stimulation (1-3). Second, the synthesis of SgII is finely regulated by mechanisms generally operating on other hormones and neuropeptides $(7,11,33,34)$. Third, like neuropeptide precursors, SgII contains several pairs of basic residues that represent po- tential cleavage sites by the subtilisin/kexin-like PCs $(35,36)$. The conservation of particular regions of SgII throughout vertebrates, the occurrence of free peptides corresponding precisely to these conserved regions in fetal and adult tissues (Ref. 32 and this study), and the fact that one of them (SN) exerts biological activities (15-19) argue for a role of SgII as a precursor to several bioactive peptides. Further studies are clearly required to determine the possible activities of EM66.

However, SgII may exert functions other than that of a peptide precursor. It has been suggested that SgII and other granins play also a role in prohormone packaging and secretory granule formation in neuroendocrine and neuronal cells. This assumption is based on the selective ability of granins to aggregate in high calcium and acidic $\mathrm{pH}$ conditions $(6,37)$. Such conditions are found in the trans-Golgi network, where biogenesis of secretory granules begins. The aggregation of granins in this compartment could assist the sorting of other secretory granule constituents and/or contribute to the biogenesis of secretory granules $(3,6,37)$. Thus, an alternative function of some of the conserved domains of SgII such as EM66 would be to participate in these intracellular trafficking events. The processing of such particular domains could be a prerequisite for their intracellular function. Consistent with this hypothesis is the finding that the neuroendocrine polypeptide 7B2, an acidic polypeptide that is considered a member of the granin family $(1,2)$, acts as a chaperone for the prohormone convertase PC2 and as an 
FIG. 8. Reverse phase HPLC analysis of EM66-LI in adult (A) and fetal (B) human adrenal glands. Tissue extracts were prepurified on Sep-Pak cartridges and chromatographed onto a Vydac $\mathrm{C}_{18}$ column. Fractions $(0.5 \mathrm{~mL} /$ fraction $)$ were collected, dried, and radioimmunoassayed for EM66. The bar above the pics indicates the elution position of recombinant EM66.
A

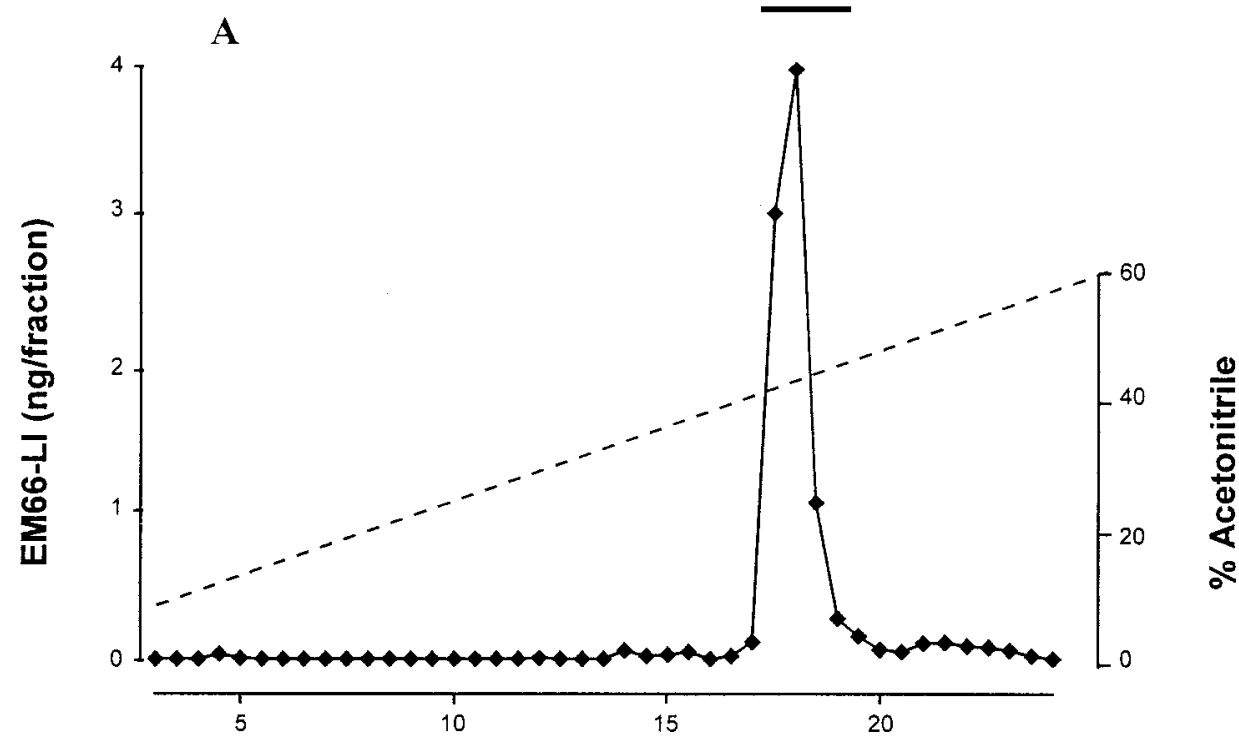

B

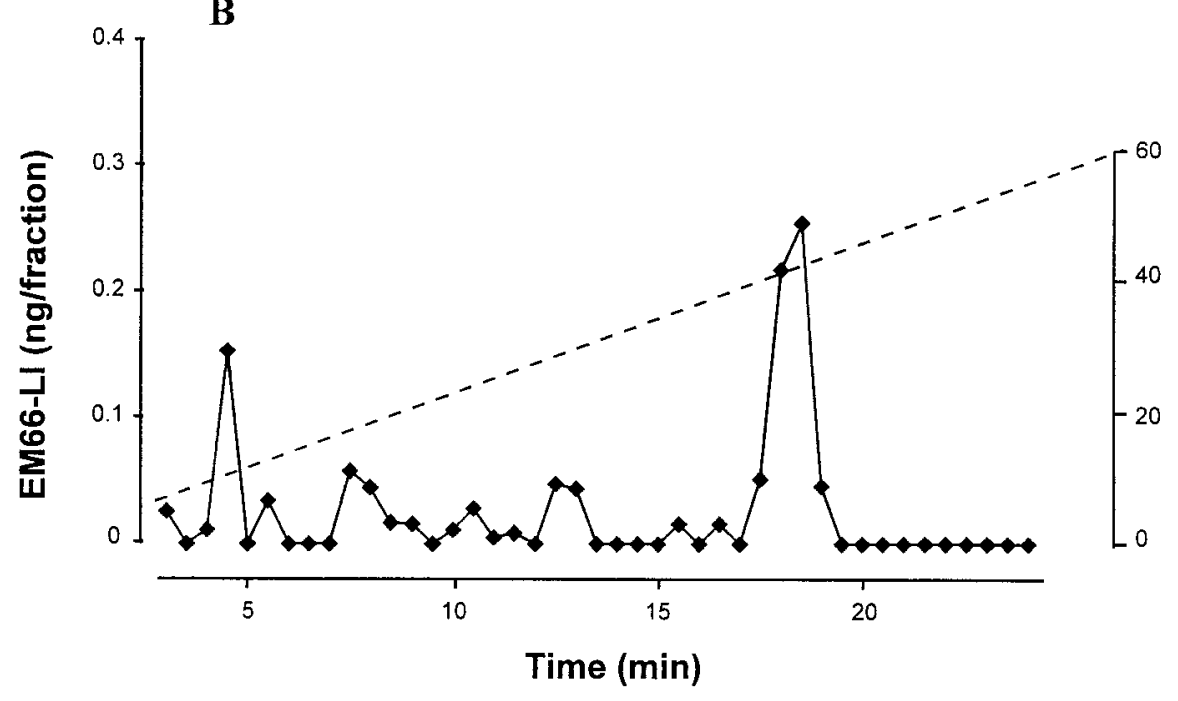

inhibitor of the activity of this enzyme through two separate and conserved regions in its sequence that are processed in vivo $(38,39)$. In addition, it has been recently shown that overexpression of $\mathrm{CgB}$ in AtT20 cells resulted in increased storage and secretion of some of the POMC-processing products (40). Together, these observations suggest that specific domains of granins, in particular those with conserved sequences across different species, bind to certain secretory products to facilitate their sorting, secretion, and/or activity.

In conclusion, the present study has revealed the existence of a novel SgII-derived peptide in the human adrenal gland. The conservation of the sequence of EM66 in vertebrates and its occurrence early during ontogenesis of the human adrenal gland strongly suggest that this peptide could exert physiological activities. The production of the recombinant EM66 peptide and the development of specific antibodies described in this report will be instrumental to define the function of this novel SgII-derived peptide.

\section{Acknowledgments}

The authors thank Dr. J. Duval (University of Rennes, Rennes, France) for providing the human SgII cDNA and the VV493-P antiserum, Drs. C. Loutelier and C. Lange (Centre Régional Universitaire de Spectroscopie, University of Rouen, Mont-Saint-Aignan, France) for mass spectrometry analysis, Dr. V. Contesse for supplying human adrenal tissue, and Drs. M. C. Tonon and D. Vieau for their help and advice during this study.

\section{References}

1. Winkler H, Fischer-Colbrie R. 1992 The chromogranins A and B: the first 25 years and future perspectives. Neuroscience. 49:497-528.

2. Iacangelo AL, Eiden LE. 1995 Chromogranin A: current status as a precursor for bioactive peptides and a granulogenic/sorting factor in the regulated secretory pathway. Regul Pept. 58:65-88.

3. Fischer-Colbrie R, Laslop A, Kirchmair R. 1995 Secretogranin II: molecular properties, regulation of biosynthesis and processing to the neuropeptide secretoneurin. Prog Neurobiol. 46:49-70.

4. Wiedenmann B, Huttner WB. 1989 Synaptophysin and chromogranins/secretogranins widespread constituents of distinct types of neuroendocrine vesicles and new tools in tumor diagnosis. Virchows Arch B Cell Pathol. 58:95-121. 
5. Rosa P, Gerdes HH. 1994 The granin protein family: markers for neuroendocrine cells and tools for the diagnosis of neuroendocrine tumors. J Endocrinol Invest. 17:207-225.

6. Gerdes H-H, Rosa P, Phillips E, et al. 1989 The primary structure of human secretogranin II, a widespread tyrosine-sulfated secretory granule protein that exhibits low-pH- and calcium-induced aggregation. J Biol Chem. 264:12009-12015.

7. Fischer-Colbrie R, Gutierrez J, Hsu CM, Iacangelo A, Eiden LE. 1990 Sequence analysis, tissue distribution and regulation by cell depolarization, and second messengers of bovine secretogranin II (chromogranin C) mRNA. J Biol Chem. 265:9208-9213.

8. Gerdes H-H, Phillips E, Huttner WB. 1988 The primary structure of rat secretogranin II deduced from a cDNA sequence. Nucleic Acids Res. 16:11811.

9. Schimmel A, Bräunling O, Rüther U, Huttner WB, Gerdes H-H. 1992 The organisation of the mouse secretogranin II gene. FEBS Lett. 314:375-380.

10. Anouar Y, Jégou S, Alexandre D, Lihrmann I, Conlon MJ, Vaudry H. 1996 Molecular cloning of frog secretogranin II reveals the occurrence of several highly conserved potential regulatory peptides. FEBS Lett. 394:295-299.

11. Holthuis JCM, Martens GJM. 1996 The neuroendocrine proteins secretogranin II and III are regionally conserved and coordinately expressed with proopiomelanocortin in Xenopus intermediate pituitary. J Neurochem. 66:2248-2256.

12. Vaudry H, Conlon MJ. 1991 Identification of a peptide arising from the specific post-translation processing of secretogranin II. FEBS Lett. 284:31-33.

13. Kirschmair R, Hogue-Angeletti R, Gutierrez J, Fischer-Colbrie R, Winkler H. 1993 Secretoneurin-a neuropeptide generated in brain, adrenal medulla and other endocrine tissues by proteolytic processing of secretogranin II (chromogranin C). Neuroscience. 53:359-365.

14. Leitner B, Fischer-Colbrie R, Scherzer G, Winkler H. 1996 Secretogranin II: relative amounts and processing to secretoneurin in various rat tissues. J Neurochem. 66:1312-1317.

15. Agneter E, Sitte HH, Stöckel-Hiesleitner S, Fischer-Colbrie R, Winkler H, Singer EA. 1995 Sustained dopamine release induced by secretoneurin in the striatum of the rat: a microdialysis study. J Neurochem. 65:622-625.

16. Simonneaux V, Vuillez P, Eder U, Miguez JM, Pévet P, Fischer-Colbrie R. 1997 Secretoneurin: a new neuropeptide in the rodent pineal gland. Cell Tissue Res. 288:427-434.

17. Reinisch N, Kirchmair R, Kähler CM, et al. 1993 Attraction of human monocytes by the neuropeptide secretoneurin. FEBS Lett. 334:41-44.

18. Kähler CM, Bellman R, Reinisch N, Schratzberger P, Gruber B, Wiedermann CJ. 1996 Stimulation of human skin fibroblast migration by the neuropeptide secretoneurin. Eur J Pharmacol. 304:135-139.

19. Kähler CM, Kirchmair R, Kaufmann G, et al. 1997 Inhibition of proliferation and stimulation of migration of endothelial cells by secretoneurin in vitro. Arterioscler Thromb Vasc Biol. 17:932-939.

20. Fischer-Colbrie R, Schober M. 1987 Isolation and characterization of chromogranins A, B, and C from bovine chromaffin granules and a rat phaeochromocytoma. J Neurochem. 48:262-270.

21. Schmid KW, Dockhorn-Dworniczak B, Fahrenkamp A, et al. 1993 Chromogranin A, secretogranin II and vasoactive intestinal peptide in phaeochromocytomas and ganglioneuromas. Histopathology. 22:527-533.

22. Vallet VS, Griffond B, Clavequin MC, De Monti M, Fellmann D, Duval J. 1995 Early detection of secretogranin II (SgII) in the human fetal pituitary: immunocytochemical study using an antiserum raised against a human recombinant SgII. Endocrinology. 136:2074-2081.
23. Laemmli UK. 1970 Cleavage of structural proteins during the assembly of the head of bacteriophage T4. Nature. 227:680-685.

24. Anouar Y, Duval J. 1991 Differential expression of secretogranin II and chromogranin A genes in the female rat pituitary through sexual maturation and estrous cycle. Endocrinology. 128:1374-1380.

25. Streeter GL. 1920 Weight, sitting height, head size, foot length and menstrual age of the human embryo. Contr Embryol. 11:143-179.

26. Yon L, Feuilloley M, Chartrel N, Arimura A, Fournier A, Vaudry H. 1993 Localization, characterization and activity of pituitary adenylate cyclase-activating polypeptide in the frog adrenal gland. J Endocrinol. 139:183-194.

27. Anouar Y, McArthur L, Cohen L, Iacangelo A, Eiden LE. 1994 Identification of a TPA-responsive element mediating preferential transactivation of the galanin gene promoter in chromaffin cells. J Biol Chem. 269:6823-6831.

28. Nussdorfer GG. 1996 Paracrine control of adrenal cortical function by medullary chromaffin cells. Pharmacol Rev. 48:495-530.

29. Schmid KW, Kunk B, Kirchmair R, Tötsch M, Böcker W, Fischer-Colbrie R. 1995 Immunohistochemical detection of secretoneurin, a novel neuropeptide endoproteolytically processed from secretogranin II, in normal human endocrine and neuronal tissues. Histochem J. 27:473-481.

30. Rouillé Y, Duguay SJ, Lund K, et al. 1995 Proteolytic processing mechanisms in the biosynthesis of neuroendocrine peptides: the subtilisin-like proprotein convertases. Front Neuroendocrinol. 16:322-361.

31. Muller L, Tougard C. 1995 Production and secretion of N-terminal secretogranin II derived peptides in GH3B6 prolactin cells. Mol Cell Endocrinol. 112:101-112.

32. Leitner B, Kaufmann WA, Marksteiner J, et al. 1997 Ontogenic development of secretogranin II and its processing to secretoneurin in rat brain. Dev Brain Res. 100:161-168.

33. Anouar Y, Benie T, De Monti M, Counis R, Duval J. 1991 Estradiol negatively regulates secretogranin II and chromogranin A messenger ribonucleic acid levels in the female rat pituitary but not in the adrenal. Endocrinology. 129:2393-2399.

34. Scammell JG, Sumners C, Reutter MA, Valentine DL, Jones LC. 1995 Regulation of secretogranin II mRNA in rat neuronal cultures. Mol Brain Res. 33:326-332.

35. Hoflehner J, Eder U, Laslop A, Seidah NG, Fischer-Colbrie R, Winkler H. 1995 Processing of secretogranin II by prohormone convertases: importance of PC1 in generation of secretoneurin. FEBS Lett. 360:294-298.

36. Dittié AS, Tooze SA. 1995 Characterization of the endopeptidase PC2 activity towards secretogranin II in stably transfected PC12 cells. Biochem J. 310:777-787.

37. Chanat E, Huttner WB. 1991 Milieu-induced, selective aggregation of regulated secretory proteins in the trans-golgi network. J Cell Biol. 115:1505-1519.

38. Braks JAM, Martens GJM. 1994 7B2 is a neuroendocrine chaperone that transiently interacts with prohormone convertase PC2 in the secretory pathway. Cell. 78:263-273.

39. Spijker S, Smit AB, Martens GJM, Geraerts WPM. 1997 Identification of a molluscan homologue of the neuroendocrine polypeptide 7B2. J Biol Chem. 272:4116-4120.

40. Natori S, Huttner WB. 1996 Chromogranin B (secretogranin I) promotes sorting to the regulated secretory pathway of processing intermediates derived from a peptide hormone precursor. Proc Natl Acad Sci USA. 93:4431-4436. 